\title{
Antioxidant and hypoglycemic activities of various solvent fractions of methanol extract of Terminalia alata Heyne ex Roth trunk-bark
}

\author{
Quang - Vinh Nguyen ${ }^{1, \bigotimes}$, Pham Van Hung ${ }^{2}$, Anh Dzung Nguyen ${ }^{1}$ \\ ${ }^{1}$ Institute of Biotechnology and Environment, Tay Nguyen University, 567 Le Duan Rd., Buon Ma Thuot city, 630000, Dak Lak \\ province, Vietnam \\ ${ }^{2}$ International University, Vietnam National University in Ho Chi Minh City, Quarter 6, Linh Trung Ward, Thu Duc District, \\ Ho Chi Minh City, Vietnam
}

$\triangle$ Corresponding author:vinh12b@gmail.com

\section{Article info}

\section{Article history:}

Received: $7^{\text {th }}$ November 2020

Accepted: $16^{\text {th }}$ February 2021

\section{Keywords:}

$\alpha$-amylase and $\alpha$-glucosidase inhibitors

Anti-hyperglycemic

DPPH radical scavenging

Terminalia alata

\begin{abstract}
The antioxidant and hypoglycemic capacities of various solvent fractions from the trunk-bark methanol extract of Terminalia alata Heyne ex Roth (T.alata) were investigated. The DPPH radical scavenging assay was used to evaluate the antioxidant activity, and the methods for determination of digestive enzymes inhibitory activity and fasting blood glucose reduction capacity in diabetic rats were used to determine the hypoglycemic activity of the extract fractions. The results indicated that higher total phenolics content was measured with increasing polarity of extraction solvent and DPPH radical scavenging activity coincided with phenolics content. Ethyl acetate fraction (EAF), n-butanol fraction (BF), and water fraction (WF) were obtained. They possessed $\alpha$-amylase inhibition with the $\mathrm{IC}_{50}$ values of $0.056 \pm 0.001,0.138 \pm 0.005$, and $0.022 \pm 0.001 \mathrm{mg}^{\mathrm{m}} \mathrm{mL}^{-1}$, respectively, which were lower than acarbose $\left(\mathrm{IC}_{50}=0.154 \pm 0.02 \mathrm{mg} \cdot \mathrm{mL}^{-1}\right)$. In contrast, $\mathrm{IC}_{50}$ values of $\alpha$ glucosidase inhibitory activities of these fractions were higher than those of acarbose. In addition, these fractions also lowered fasting blood glucose concentrations in streptozotocin induced diabetic rats at a dose of $200 \mathrm{mg} \cdot \mathrm{kg}^{-1} \mathrm{bw}$ (body weight) without inducing body weight loss, which was not observed when treating with acarbose. The EAF and WF of trunk-bark of $T$. alata are recommended as potent sources for further research on antioxidant and hypoglycemic activities.
\end{abstract}

\section{Introduction}

Genus Terminalia comprises more than 250 species (Cock 2015), while several of them have been used as traditional medicines in Asian countries including Vietnam. Recently, bioactivities of Terminalia species have been reported by numerous authors. Solvent extracts of leaves and trunk-bark of $T$. nigrovenulosa showed strong antioxidant and antimicrobial activities (Nguyen and Eun 2011; 2013). Moreover, methanol extract of $T$. chebula fruits has antioxidant (Lee et al. 2007), antimicrobial (Malekzadeh et al. 2001), antidiabetic (Gao et al. 2007), and anticancer (Sabu and Ramadasan 2002; Saleem et al. 2002) activities.

Terminalia alata Heyne ex Roth ( $T$. atala) belonging to the Combretaceae family is widely grown in deciduous forests in the southern part of Vietnam. T. alata plants have been used as 
traditional remedies for anti-diarrhea in the treatment of chronic dysentery, sore throat, laryngitis, and hemorrhoids. Nguyen et al. (2016) indicated that the methanol extract of $T$. alata trunk bark possessed antioxidant efficiency and hypoglycemic capacity in streptozocine induced rat model. However, effectiveness of different solvents on the solubility of bioactive compounds and their corresponding bioactivities has not yet been studied. Several reports mentioned that the bioactive components in the plants concentrated on different solvent fractions depending on plant species. Khled khoudja et al. (2014) indicated that water fraction (WF) of $T$. algeriensis was the most effective fraction amongst these investigated solvent fractions, whereas the highest antioxidant activity of Combretum erythrophyllum (Burch.) was found in ethyl acetate fraction (EAF) (Fanyana et al. 2017). Report of Emran et al. (2015) indicated that chloroform fraction (CF) expressed the highest clot lysis activity. Therefore, this research aims to investigate the antioxidant and hypoglycemic activities of different solvent fractions of $T$. alata to reveal their potency for the highest bioactivities.

\section{Experimental}

\section{Chemicals}

2,2-diphenyl-2-picrylhydrazyl hydrate, gallic acid, Folin-Ciocalteu reagent, potassium ferricyanide, sodium nitrite, aluminium chloride, streptozotocin, pancreatic $\alpha$-amylase, rat intestinal acetone powder, p-nitrophenyl- $\alpha$-D-glucopyranoside, and dinitrosalicylic (DNS) acid were purchased from SigmaAldrich (St. Louis, MO, USA). Other chemicals and reagents reached the analytical grade.

\section{Plant samples}

The collection of the trunk bark of $T$. alata was located in Yok Don National Park, Dak Lak Province, Vietnam. After cutting out from the tree, the barks were dried at ambient temperature with active ventilation to obtain the moisture of $6 \%$, ground by grinder using a cutting mill (LMM010W, LiHOM Inc., Seoul, Korea) and then stored at $-30{ }^{\circ} \mathrm{C}$ in polyethylene (PE) bags or directly use.

The dried trunk-bark powder was extracted three times with methanol by maceration method as reported by Nguyen et al. (2016). Briefly, the extraction was carried out using a ratio of trunkbark/methanol of $1: 10(\mathrm{w} / \mathrm{v})$, shaking at room temperature for $24 \mathrm{~h}$ and then filtering through filter paper (No. 1). The residue was then extracted twice more with methanol as described above. The extracts were combined and concentrated at $60{ }^{\circ} \mathrm{C}$ under vacuum using a rotary evaporator (IKA, Germany) to obtain the crude extract. The crude extract was then dissolved in distilled water at a ratio of crude extract/distilled water of $1: 5(\mathrm{w} / \mathrm{v})$ for fractionation. The aqueous solution was further partitioned with different solvents as described by Nguyen et al. (2015). Briefly, partition with hexane obtained the hexane fraction (HF) and the aqueous fraction was sequentially partitioned with chloroform, ethyl acetate an n-butanol. The chloroform (CF), ethyl acetate (EAF), and nbutanol (BF) fractions were filtered and dried by evaporation under vacuum. The final aqueous fraction (WF) was filtered and dried by freezing dryer.

\section{Animal}

The 5-week old Wistar albino rats weighed $20-25$ $\mathrm{g}$ were used for in vivo hypoglycemic activity experiments. The rats were obtained from the Institute of Vaccines and Medical Biologicals (IVAC), Nha Trang, Vietnam, kept in the plastic cage houses in $12 \mathrm{~h}$ light/ $12 \mathrm{~h}$ dark cycle room at $25 \pm 2{ }^{\circ} \mathrm{C}$ and fed with a standard rodent diet and water ad libitum before testing. The experiments were carried out under the regulation of the Institutional Animal Care and Use Committee at the Tay Nguyen Institute of Hygiene and Epidemiology, Dak Lak Province, Vietnam.

Total phenolic content of extracts was determined using Folin-Ciocalteu method with slight modification by Nguyen et al. (2016).

DPPH radical scavenging activity was followed by Nguyen et al. (2016).

Rat intestinal $\alpha$-glucosidase inhibitory activity was performed by the method of Kwon et al. (2006) 
with slight modification by Nguyen et al. (2016), using acarbose as the positive control.

The inhibition of porcine pancreatic $\alpha$-amylase activity was carried out by the method of Kwon et al. (2006) with slight modification described by Nguyen et al. (2016). Acarbose is the $\alpha$-glucosidase inhibitor and was used as the positive control.

Acute oral toxicity and glucose level in normal rat studies

Acute oral toxicity study was carried out as a slightly modified method of Organization for Economic Co-operation and Development (OECD 2001) guidelines 423 (acute toxic classic method) and described details by Nguyen et al. (2016). Briefly, fractions with the concentrations of (100, 200 and $300 \mathrm{mg} \cdot \mathrm{kg}^{-1}$ body weight) were daily oral administration of investigated fractions, animals (6 rats/each group) were observed individually at least once during the first $30 \mathrm{~min}$, periodically during the first $24 \mathrm{~h}$, with special attention given during the first $4 \mathrm{~h}$, and daily afterward, they were fed with extracts and observed for a total of 8 days for toxicity and fasting blood glucose levels determination by blood glucose meter (Bionime GM110, Bionime, Swiss).

\section{Streptozotocin-induced diabetic rats}

Ice-cold aqueous streptozotocin $\left(150 \mathrm{mg} \cdot \mathrm{kg}^{-1}\right.$ body weight) was used to treat male Wistar Albino rats intraperitoneally (Nguyen et al. 2016).

Evaluation of extracts on streptozotocin-induced diabetic rats

The experiments were described by Nguyen et al. (2016) which were carried out by single and multidose experiments. Blood glucose meter (Bionime GM110, Bionime, Switzerland) was used for measurement of fasting glucose concentrations. Acarbose has been used as medicine for controlling postprandial blood glucose. Therefore, it was used as positive control in compared to the efficiency of extracts in controlling postprandial blood glucose. Saline was used for dissolving extract fractions. Therefore, it is used as a negative control.

\section{Data analysis}

All experiments were carried out in triplicates and results were shown as the mean values with standard deviations. The significant statistic for each experiment was determined using the analysis of the variance test (ANOVA) and the LSD (Least Significant Difference). The post-test was used for the comparison of the mean values. Differences were considered significant at $p<0.05$.

\section{Results}

Total phenolics contents and DPPH inhibitory activity of $T$. alata extract fractions

Table 1 shows total phenolics contents measured in the fractions from $T$. alata. The highest values of total phenolics were obtained in more polar solvents phenolics, namely in water fraction (WF), followed by n-butanol fraction (BF), and ethyl acetate fraction (EAF). In contrast, they were almost absent in hexane fraction (HF). The inhibitory activities of fractions against DPPH are compared to a positive control (ascorbic acid) via $\mathrm{IC}_{50}$ values in Table 1.

Table 1. Total phenolics contents and DPPH inhibitory activity of the fractions from T. alata bark.

\begin{tabular}{|c|c|c|}
\hline Samples/control & $\begin{array}{c}\text { Total phenolics } \\
\text { content } \\
{\left[\begin{array}{c}\text { mg GAE.g } \\
\text { [1 dry } \\
\text { extracts] }\end{array}\right.}\end{array}$ & $\begin{array}{c}\text { DPPH radical } \\
\text { scavenging } \\
\text { activity } \\
\text { IC }_{50}\left[\mathrm{mg}^{-} \mathrm{mL}^{-1}\right]\end{array}$ \\
\hline $\mathrm{HF}$ & - & - \\
\hline $\mathrm{CF}$ & $246.329 \pm 5.530^{\mathrm{a}}$ & $3.063 \pm 0.023^{\mathrm{a}}$ \\
\hline EAF & $589.613 \pm 1.937^{b}$ & $0.290 \pm 0.010^{\mathrm{b}}$ \\
\hline $\mathrm{BF}$ & $704.694 \pm 0.927^{\mathrm{c}}$ & $0.237 \pm 0.006^{\mathrm{c}}$ \\
\hline WF & $773.349 \pm 9.151^{\mathrm{d}}$ & $0.241 \pm 0.003^{c}$ \\
\hline Ascorbic acid & - & $0.240 \pm 0.010^{\mathrm{c}}$ \\
\hline
\end{tabular}

Different letters indicate a significant difference amongst the values with a row at $p<0.05$,

(-) no detection,

$\mathrm{HF}, \mathrm{CF}, \mathrm{EAF}, \mathrm{BF}$ and WF are hexane, chloroform, ethyl acetate, n-butanol and water extract fractions, respectively.

\section{Alpha-amylase and alpha-glucosidase inhibitory activities of fractions}

The $\mathrm{IC}_{50}$ values of $\alpha$-amylase and $\alpha$-glucosidase inhibitory activities of different fractions are shown in Table 2. The results indicate that both the enzymes were inhibited by most of the extract 
fractions at the investigated concentrations, except for the HF. The strongest inhibitory activity against $\alpha$-amylase was found in the WF, followed by $\mathrm{BF}$ and EAF with the $\mathrm{IC}_{50}$ values 0.022 and 0.056 $\mathrm{mg} \cdot \mathrm{mL}^{-1}$, respectively. These fractions had higher $\alpha$-amylase inhibitory activity than acarbose (the positive control) (Table 2). In contrast, the $\alpha$ glucosidase inhibitory activity of methanol extract and fractions was lower than acarbose (Table 2). Amongst these fractions, $\mathrm{BF}$ and EAF possessed the strongest $\alpha$-glucosidase inhibitory effects, followed by WF (Table 2). Moreover, all three types of extract fractions possessed much higher inhibitory activities against both enzymes compared to that of the methanol extract. This suggests that fractionation of crude extract could concentrate the active compounds in solvent fractions.

Table 2. Effect of fractions of $T$. alata on $\alpha$-amylase and $\alpha$ glucosidase activities.

\begin{tabular}{|c|c|c|}
\hline Sample/Controls & $\begin{array}{c}\alpha \text {-glucosidase } \\
\text { inhibition } \\
\text { IC }_{50}\left(\mathrm{mg}^{-m^{-1}}\right)\end{array}$ & $\begin{array}{c}\alpha \text {-amylase } \\
\text { inhibition } \\
\mathrm{IC}_{\mathbf{5 0}}\left(\mathrm{mg}^{\left.-\mathrm{mL}^{-1}\right)}\right.\end{array}$ \\
\hline Methanol extract & $>4^{\mathrm{a}}$ & $0.13 \pm 0.01^{\mathrm{c}}$ \\
\hline $\mathrm{HF}$ & - & - \\
\hline $\mathrm{CF}$ & $3.787 \pm 0.087^{\mathrm{b}}$ & $>20^{\mathrm{a}}$ \\
\hline EAF & $1.330 \pm 0.133^{\mathrm{d}}$ & $0.056 \pm 0.001^{\mathrm{d}}$ \\
\hline $\mathrm{BF}$ & $1.251 \pm 0.059^{\mathrm{d}}$ & $0.138 \pm 0.005^{\mathrm{c}}$ \\
\hline WF & $1.729 \pm 0.025^{\mathrm{c}}$ & $0.022 \pm 0.001^{\mathrm{e}}$ \\
\hline Acarbose & $0.492 \pm 0.02^{\mathrm{e}}$ & $0.154 \pm 0.02^{\mathrm{b}}$ \\
\hline
\end{tabular}

Different letters indicate a significant difference amongst the values with a row at $p<0.05$, (-) no detection, $\mathrm{HF}, \mathrm{CF}, \mathrm{EAF}$, $\mathrm{BF}$ and WF are hexane, chloroform, ethyl acetate, n-butanol and water extract fractions, respectively.

\section{Acute toxicity study}

The normal rats were daily fed with the fractions of Terminalia atala by oral intubation at a dose of 100, 200 and 300 mg. $\mathrm{kg}^{-1}$ body weight and observed for eight days. The results in Table 3 indicated that it is non-toxic at an oral dose up to $300 \mathrm{mg} \cdot \mathrm{kg}^{-1}$ body weight in all rats being oral administration of fractions for eight days of experiment except for chloroform fraction (CF). The rats treated with $\mathrm{CF}$ at a dose of $300 \mathrm{mg} \cdot \mathrm{kg}^{-1}$ bw died after 8 days of treatment. Therefore, 200 mg. $\mathrm{kg}^{-1}$ bw was used as the safe dose for investigation of anti-hypoglycemic activity of all fractions.
Effect of single dose fractions on fasting blood glucose concentrations in diabetic rats

The effects of the safe dose of all fractions or acarbose addition on blood glucose concentrations in streptozotocin induced diabetic rats were examined (Table 4). The fasting blood glucose concentrations of streptozotocin-induced diabetic rat models used in this study ranged from 10 to 17 mmol. $\mathrm{L}^{-1}$. In the single dose evaluation, the acarbose treatment showed the maximum effect within $2-4 \mathrm{~h}$ and slightly increased after $6-8 \mathrm{~h}$. On the other hand, the EAF and WF had significant effect within $2-8 \mathrm{~h}$ and $4-8 \mathrm{~h}$, respectively. The results in Table 4 suggested that the blood glucose concentrations in diabetic rats treated with individual fractions were slowly reduced and kept constant for longer time as compared to acarbose (positive control). In this respect, the EAF was found to possess the highest effect on the reduction of glucose concentration in diabetic rats, followed by WF (Table 4). The glucose concentration decreased in rats treated with EAF after 2, 4, 6 and $8 \mathrm{~h}$, respectively. The strongest drop of glucose concentration in rats (52\%) was found upon treatment with WF for $4 \mathrm{~h}$, while the glucose concentration remained constant until $8 \mathrm{~h}$. For comparison, treatment with acarbose resulted in decreased glucose concentration to $49.66 \%$ after $2 \mathrm{~h}$ with further decrease after $8 \mathrm{~h}$.

\section{Effect of multiple dose fractions on fasting blood glucose concentrations in diabetic rats}

The changes in glucose concentration in diabetic rats treated with the fractions were shown in Table 5. Generally, the daily oral treatment with fractions at the investigation dose significantly decreased blood glucose concentrations in diabetic rats compared to the corresponding control group. The significant reduction in postprandial blood glucose concentration by the fractions and acarbose was observed after the $8^{\text {th }}$ day and remained unchanged until the $12^{\text {th }}$ day. In contrast, there was significantly increased the glucose concentration in diabetic rats treated with saline (control rats) under the same conditions. As shown in Table 5, the elevated glucose concentrations in diabetic rats were about $24.92 \%$ and $51.71 \%$ after treatment 
with saline for 8 and 12 days, respectively. Acarbose exerted a stronger effect on reduction in postprandial blood glucose concentration in diabetic rats than the fractions. As a result, both single and multiple doses of fractions showed the effective hypo-glycemic activity in streptozotocininduced rats. The results (Fig. 1) indicated the

Table 3. Effect of administration of fractions of T. alata on blood glucose level and status of normal rats.

\begin{tabular}{|c|c|c|c|c|c|}
\hline \multirow{2}{*}{ STT } & \multirow{2}{*}{$\begin{array}{l}\text { Samples/ } \\
\text { Controls }\end{array}$} & \multirow{2}{*}{$\begin{array}{c}\text { Oral dose } \\
{\left[\mathrm{mg.kg}^{-1} \text { body weight }\right]}\end{array}$} & \multicolumn{3}{|c|}{ Blood glucose concentration $\left[\mathrm{mmol} . \mathrm{mL}^{-1}\right]$} \\
\hline & & & Day 0 & Day $4^{\text {th }}$ & Day $8^{\text {th }}$ \\
\hline \multirow{3}{*}{1} & \multirow{3}{*}{$\mathrm{CF}$} & 100 & $8.23 \pm 1.06$ & $7.73 \pm 0.81$ & $7.97 \pm 0.94$ \\
\hline & & 200 & $9.20 \pm 0.95$ & $8.53 \pm 1.10$ & $8.37 \pm 0.39$ \\
\hline & & 300 & $8.83 \pm 1.10^{\mathrm{a}}$ & $7.07 \pm 0.55^{\mathrm{b}}$ & Died \\
\hline \multirow{3}{*}{2} & \multirow{3}{*}{ EAF } & 100 & $7.33 \pm 0.46$ & $6.83 \pm 0.47$ & $6.80 \pm 0.46$ \\
\hline & & 200 & $7.33 \pm 0.10$ & $7.07 \pm 0.36$ & $6.80 \pm 0.45$ \\
\hline & & 300 & $8.93 \pm 0.49$ & $8.60 \pm 0.36$ & $8.17 \pm 0.45$ \\
\hline \multirow{3}{*}{3} & \multirow{3}{*}{$\mathrm{BF}$} & 100 & $8.67 \pm 0.21$ & $7.43 \pm 0.81$ & $7.53 \pm 0.81$ \\
\hline & & 200 & $8.40 \pm 0.36$ & $7.77 \pm 0.89$ & $7.43 \pm 0.32$ \\
\hline & & 300 & $8.00 \pm 0.53$ & $8.27 \pm 0.29$ & $7.77 \pm 0.45$ \\
\hline \multirow{3}{*}{4} & \multirow{3}{*}{ WF } & 100 & $9.03 \pm 1.00$ & $8.50 \pm 0.69$ & $8.20 \pm 0.10$ \\
\hline & & 200 & $7.53 \pm 0.58$ & $7.87 \pm 0.58$ & $7.30 \pm 0.44$ \\
\hline & & 300 & $8.13 \pm 0.25$ & $7.87 \pm 0.58$ & $7.67 \pm 0.49$ \\
\hline 5 & Saline & & $9.00 \pm 1.81$ & $8.50 \pm 0.35$ & $7.73 \pm 0.66$ \\
\hline
\end{tabular}

Different letters indicate a significant difference amongst the values with a row at $p<0.05, \mathrm{CF}, \mathrm{EAF}, \mathrm{BF}$ and WF are hexane, chloroform, ethyl acetate, n-butanol and water extract fractions, respectively.

Table 4. Fasting blood glucose concentrations in diabetic rats (single dose) treated with fractions at a dose of $200 \mathrm{mg}^{\mathrm{kgg}}{ }^{-1} \mathrm{body}$ weight.

\begin{tabular}{|c|c|c|c|c|c|}
\hline \multirow{2}{*}{ Samples/ Controls } & \multicolumn{5}{|c|}{ Blood glucose concentration $\left[\mathrm{mmol}^{\mathrm{L}} \mathrm{L}^{-1}\right]$} \\
\hline & $\mathbf{O} \mathbf{h}$ & $2 \mathrm{~h}$ & $4 \mathrm{~h}$ & $6 \mathrm{~h}$ & $8 \mathrm{~h}$ \\
\hline $\mathrm{CF}$ & $12.18 \pm 0.98^{b}$ & $12.56 \pm 0.70^{b}$ & $12.83 \pm 1.25^{\mathrm{a}}$ & $14.76 \pm 1.04^{\mathrm{a}}$ & $14.19 \pm 0.98^{\mathrm{a}}$ \\
\hline EAF & $11.53 \pm 1.10^{\mathrm{a}}$ & $8.27 \pm 1.75^{\mathrm{b}}$ & $6.80 \pm 1.65^{\mathrm{b}}$ & $7.87 \pm 2.39^{\mathrm{b}}$ & $7.63 \pm 1.53^{b}$ \\
\hline $\mathrm{BF}$ & $12.07 \pm 0.35^{\mathrm{a}}$ & $10.77 \pm 0.74^{\mathrm{a}}$ & $11.73 \pm 1.45^{\mathrm{a}}$ & $12.00 \pm 0.72^{\mathrm{a}}$ & $9.13 \pm 1.17^{\mathrm{a}}$ \\
\hline WF & $14.23 \pm 1.50^{\mathrm{a}}$ & $10.90 \pm 4.66^{\mathrm{a}}$ & $6.83 \pm 0.25^{\mathrm{b}}$ & $7.00 \pm 0.95^{\mathrm{b}}$ & $7.17 \pm 2.06^{\mathrm{b}}$ \\
\hline Positive control (acarbose) & $14.10 \pm 1.93^{\mathrm{a}}$ & $7.10 \pm 0.95^{\mathrm{b}}$ & $8.17 \pm 1.52^{b}$ & $9.10 \pm 0.62^{b}$ & $12.23 \pm 2.06^{\mathrm{a}}$ \\
\hline Negative control (saline) & $13.40 \pm 2.0^{\mathrm{a}}$ & $12.30 \pm 1.9^{\mathrm{a}}$ & $13.60 \pm 2.1^{\mathrm{a}}$ & $15.40 \pm 1.8^{\mathrm{b}}$ & $16.50 \pm 1.0^{\mathrm{b}}$ \\
\hline
\end{tabular}

Different letters indicate a significant difference in time at $p<0.05, \mathrm{CF}, \mathrm{EAF}, \mathrm{BF}$ and WF are hexane, chloroform, ethyl acetate, n-butanol and water extract fractions, respectively.

Table 5. Effect of fractions on blood glucose concentrations in diabetic rats as treatment days (multiple dose).

\begin{tabular}{lcccc}
\hline \multirow{2}{*}{ Samples / controls } & \multicolumn{4}{c}{ Concentration of blood glucose [mMol.L ${ }^{-1}$ ] } \\
\cline { 2 - 5 } & Day 0 & Day 4 & Day 8 $^{\text {th }}$ & Day 12 $^{\text {th }}$ \\
\hline EAF & $13.43 \pm 2.14^{\mathrm{a}}$ & $11.53 \pm 4.40^{\mathrm{a}}$ & $8.67 \pm 0.75^{\mathrm{b}}$ & $8.00 \pm 0.20^{\mathrm{b}}$ \\
BF & $13.03 \pm 1.61^{\mathrm{a}}$ & $11.80 \pm 1.25^{\mathrm{a}}$ & $8.80 \pm 1.56^{\mathrm{b}}$ & $8.40 \pm 1.15^{\mathrm{b}}$ \\
WF & $13.70 \pm 1.80^{\mathrm{a}}$ & $10.53 \pm 0.61^{\mathrm{a}}$ & $9.80 \pm 0.60^{\mathrm{b}}$ & $8.60 \pm 0.70^{\mathrm{b}}$ \\
Positive control (acarbose) & $13.20 \pm 3.21^{\mathrm{a}}$ & $10.00 \pm 5.90^{\mathrm{a}}$ & $6.90 \pm 3.75^{\mathrm{b}}$ & $5.93 \pm 2.27^{\mathrm{b}}$ \\
Diabetic rats (saline) & $10.70 \pm 0.50^{\mathrm{b}}$ & $10.70 \pm 1.22^{\mathrm{b}}$ & $13.37 \pm 2.42^{\mathrm{ab}}$ & $16.23 \pm 3.19^{\mathrm{a}}$ \\
Normal mouse (saline) & $7.43 \pm 0.32^{\mathrm{a}}$ & $7.53 \pm 0.46^{\mathrm{a}}$ & $7.10 \pm 0.66^{\mathrm{a}}$ & $6.90 \pm 0.79^{\mathrm{a}}$ \\
\hline
\end{tabular}

Different letters indicate a significant difference in time at $p<0.05$,

$\mathrm{EAF}, \mathrm{BF}$ and WF are hexane, chloroform, ethyl acetate, n-butanol and water extract fractions, respectively.

change of body weight of diabetic rats treated with multiple doses of the individual fraction or acarbose (positive control) during 12 days. The body weight of diabetic rats treated with saline (negative control) was slightly increased until the 8 days $(7 \%)$ and then trended to reduce after 12 days. In contrast, the body weight of the acarbosetreated diabetic rats significantly decreased after 8 days of treatment (13\%) and $16 \%$ after 12 days of treatment. However, the diabetic rat groups treated 
with fractions had no significant change in body weight during treatment duration (Fig. 1).

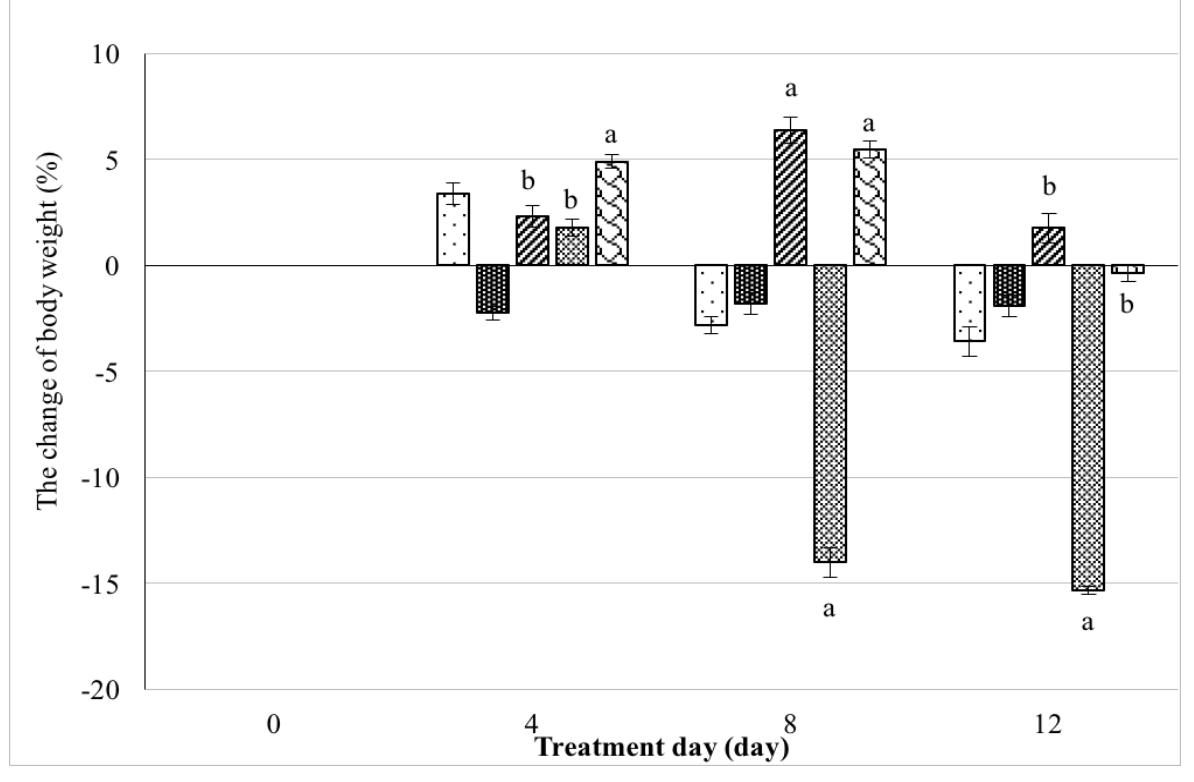

Fig. 1. Effects of fractions on body weight of diabetic rats (multiple doses). Different letters above the bars for the same fraction-treatment or saline-treatment or acarbosetreatment indicate statistically significant differences at $p<0.05$.

$\square$ EAF, $\mathbf{W}$.WF, EE BF, Saline (negative control), 7. Acarbose (positive control). EAF, BF and WF are hexane, chloroform, ethyl acetate, n-butanol and water extract fractions, respectively.

\section{Discussion}

The research related to the development of new compounds for prevention of diseases has been recently increased, particularly regarding the role of flavonoids and phenolic acids as antioxidants (Lopez-Velez et al. 2003). Furthermore, the phenolic compounds possess several biological activities that play important roles in disease prevention, including antioxidant and antidiabetic activities (Kunyanga et al. 2012). According to a report of Vats et al. (2002), the hypoglycemic activity of most medicinal plants was due to the action of phytochemicals which might reduce the activity of starch hydrolyzing enzymes in track to retard the sharply raising in postprandial blood glucose concentration in diabetic patients. Moreover, phytochemicals proved that they could promote insulin secretion and/or improve effective glucose transport and metabolism in muscle (Gray 1995). Therefore, a number of evaluations of medicinal plants extracts as well as isolated components from the plants as natural sources for inhibition of starch hydrolyzing enzyme and control the postprandial blood glucose concentration in diabetic rats have been done so far. Nguyen et al. (2016) showed that the crude extract of $T$. atala possessed a relatively high effect on both starch hydrolyzing enzymes inhibition and hypoglycemic activity in diabetic rats.

Several reports indicated that active compounds with different polarity might be present in the plant, and there was a relationship between amounts of phenolic compounds containing in extracts and biological capacity (Khled khoudja et al. 2014; Emran et al. 2015; Fanyana et al. 2017). AbarcaVargas et al. (2016) indicated that the phenolics compounds appeared to be dependent on the type of solvent used, its polarity index, and the solubility of phenolics compounds in the extraction solvent. The finding in this study showed that fractions which contained higher content of total phenolics also possessed a stronger DPPH radical scavenging activity (Table 1). The results in this study are in accordance with many reports (Piljac-Žegarac et al. 2005; Nguyen and Eun 2011; Kunyanga et al. 2012; Chai and Wong 2012). However, the direct correlation between the inhibition capacity against $\alpha$-glucosidase activity and total phenolics contents was not observed in this study. EAF and BF containing medium content of total phenolics possessed the strongest $\alpha$-glucosidase inhibitory effect, followed by WF (Table 2). However, the highest inhibition of $\alpha$-amylase activity was found in WF containing the highest total phenolics 
content compared to EAF and BF. Results could be explained that the enzyme inhibitory activity of fractions depended on both the total number of phenolic compounds and the structure characteristics of individual phenolics in the extracts (Pulido and Saura-Calixto 2000; Gálvez et al. 2005; Kwon et al. 2006). Hyperglycemia is a phenomenon that occurred in type 2 diabetes patients that the glucose concentration in blood suddenly increases due to the hydrolysis of starch by pancreatic $\alpha$-amylase and intestinal $\alpha$ glucosidase to glucose that is easily absorbed by the small intestine (Gray 1995). Therefore, the efficient method to control type 2 diabetes is the utilization of intestinal $\alpha$-glucosidase and pancreatic $\alpha$-amylase inhibitors due to their potent therapy to control hyperglycemia (Krentz and Bailey 2005). The extracts of several Terminalia species possessed anti-hyperglycemic activity. Nguyen et al. (2016) presented that methanol extract of $T$. alata possessed $\alpha$-amylase and $\alpha$ glucosidase inhibitory activities as well as antihyperglycemic activity in diabetic rats. As the results presented by Sabu and Kuttan (2002), the methanol extracts of $T$. chebula and T. belerica at a dose of $100 \mathrm{mg} \cdot \mathrm{kg}^{-1}$ body weight decreased $12.7 \%$ and $13.1 \%$ of glucose in diabetic rats after 4 hours treatment, respectively. The results of our previous study also indicated that the crude extracts of $T$. belirica and T. alata at a dose of $200 \mathrm{mg} \cdot \mathrm{kg}^{-1} \mathrm{bw}$ reduced $45.40 \%$ and $46.01 \%$ of glucose in diabetic rats after 4-h treatment, respectively (Nguyen et al. 2016), similar to reduction rate of glucose in diabetic rats treated with WF and EAF at the same conditions in this study. Moreover, similar to the crude extract, the fractions also had no significant effect on glucose concentration in normal rats at a dose of $200 \mathrm{mg} \cdot \mathrm{kg}^{-1}$ body weight because a homeostasis in normal rats could control the normal regulatory mechanisms involved in carbohydrate metabolism (Vats et al. 2002). In contrast, the fractions showed hypoglycemic activity in diabetic rats in both single and multiple doses (Table 5). The significant reduction in blood glucose concentration in diabetic rats was found after the 8-day treatment with all fractions and acarbose (Table 5) and kept constant until the $12^{\text {th }}$ day. Table 4 expresses that the fractions which possessed high $\alpha$-amylase inhibitory effect represented a strong effect on lowering blood glucose concentration in diabetic rats. Thus, $\alpha$ amylase inhibitors could be considered as the effective drug for post-prandial hyperglycemia treatment because of the inhibition of gluconeogenesis and reduction of glucose absorption (Youn et al. 2004).

\section{Conclusions}

The current study found that ethyl acetate and water extract fractions from $T$. alata contained relatively high amount of phenolic contents. These fractions showed relatively high antioxidant activity and inhibitory activities against starchhydrolyzing enzymes. Especially, these fractions significantly reduced blood glucose concentration in diabetic rats, which could be used for postprandial hyperglycemia treatment. Further research on isolation and identification of the individual active compounds from ethyl acetate and water extract fractions as well as evaluation of their in vivo antioxidant activities and lowering blood glucose concentration in diabetic rats should be carried out in the future.

\section{Acknowledgements}

This research is funded by Vietnam National Foundation for Science and Technology Development (NAFOSTED) under the grant number 106.99-2020.17.

\section{Conflict of Interest}

The authors declare that they have no conflict of interest.

\section{References}

Abarca-Vargas R, Malacara CFP, Petricevich VL (2016) Characterization of chemical compounds with antioxidant and cytotoxic activities in Bougainvillea $\mathrm{x}$ buttiana Holttum and Standl, (var. Rose) extracts. Antioxidants. 5: 45.

Chai TT, Wong FC (2012) Whole-plant profiling of total phenolic and flavonoid contents, antioxidant capacity and nitric oxide scavenging capacity of Turnera subulata. J. Med. Plants Res. 6: 1730-5.

Cock IE (2015) The medicinal properties and phytochemistry of plants of the genus Terminalia (Combretaceae). Inflammopharmacol. 23: 203-29.

Emran TB, Rahman MA, Uddin M MN, Rahman M M, Uddin MZ, Dash R and Layzu C (2015) Effects of organic extracts and their different fractions of five Bangladeshi 
plants on in vitro thrombolysis. BMC Complementary Alt. Med. 15: 128.

Fanyana MM, Ikechukwu PE, Imelda L, Aroke A, Vusumzi EP, Michael JK, Sekomeng JM (2017) Solvent-solvent fractionations of Combretum erythrophyllum (Burch.) leave extract: Studies of their antibacterial, antifungal, antioxidant and cytotoxicity potentials. Asian Pacific J. Trop. Med. 10: 670-679.

Gálvez M, Martín-Cordero C, Houghton PJ, Ayuso MJ (2005) Antioxidant activity of methanol extracts obtained from Plantago species. J. Agric. Food Chem. 23: 1927-33.

Gao H, Huang YN, Xu PY, Kawabata J (2007) Inhibitory effect on $\alpha$-glucosidase by the fruits of Terminalia chebula Retz. Food Chem. 105: 628-34.

Gray DM (1995) Carbohydrate digestion and absorption-role of small intestine. New Engl. J. Med. 29: 1225-30.

Khled khoudja N, Boulekbache-Makhlouf L, Madani K (2014) Antioxidant capacity of crude extracts and their solvent fractions of selected Algerian Lamiaceae. Ind. Crops Prod. 52: 177-182.

Krentz AJ, Bailey CJ (2005) Oral antidiabetic agents: current role in type 2 diabetes mellitus. Drugs. 65: 385-411.

Kunyanga CN, Imungi JK, Okoth MW, Biesalski HK, Vadivel V (2012) Total phenolic content, antioxidant and antidiabetic properties of methanolic extract of raw and traditionally processed Kenyan indigenous food ingredients. LWT - Food Sci. Technol. 45: 269-76.

Kwon YI, Vattem DA, Shetty K (2006) Evaluation of clonal herbs of Lamiaceae species for management of diabetes and hypertension. Asian Pacific J. Clin. Nutr. 15: 107-18.

Lee HS, Jung SH, Yun BS, Lee KW (2007) Isolation of chebulic acid from Terminalia chebula Retz. and its antioxidant effect in isolated rat hepatocytes. Arch. Toxicol. 81: 211-18.

Lopez-Velez M, Martinez-Martine F, Del Valle-Ribes C (2003) The study of phenolic compounds as natural antioxidants in wine. Critical Rev. Food Sci. Nutr. 43: 233-44.

Malekzadeh F, Ehsanifar H, Shahamat M, Levin M, Colwell RR (2001) Antibacterial activity of black myrobalan (Terminalia chebula Retz.) against Helicobacter pylori. Int. J. Antimicrob. Ag. 18: 85-88.

Nguyen QV, Eun JB (2011) Antioxidant activity of solvent extracts from Vietnamese medicinal plants. J. Med. Plants Res. 5: 2798-2811.

Nguyen QV, Eun JB (2013) Antimicrobial activity of solvent extracts from Vietnamese medicinal plants. J. Med. Plants Res. 4: 2597-2605.

Nguyen QV, Eun JB, Kim DW, Wang SL (2015) Effect of Terminalia nigrovenulosa extracts and its isolated compounds on intracellular ROS generation and MMP expression in HT1080 cells. Res. Chem. Intermed. 42: 2055-2073.

Nguyen QV, Nguyen VB, Eun JB, Wang SL, Nguyen DH, Tran TN, Nguyen AD (2016) Antioxidant and antidiabetic effect of some medicinal plants belong to Terminalia species collected in Dak Lak Province, Vietnam. Res. Chem. Intermed. 42: 5859-5871.
OECD (2001) OECD guidelines for testing of chemicals. Test No. 423: Acute oral toxicity-acute toxic class method. Paris: OECD.

Piljac-Žegarac J, Martinez S, Valek L, Stipčević T, Kovačević-Ganić K (2005) Correlation between the phenolic content and DPPH radical scavenging activity of selected Croatian wines. Acta Alimentaria. 36: 185-193.

Pulido R, Bravo L, Saura-Calixto F (2000) Antioxidant activity of dietary phenolicss as determined by a modified ferric reducing/antioxidant power assay. J. Agric. Food Chem. 48: 3396-402.

Sabu MC, Ramadasan K (2002) Anti-diabetic activity of medicinal plants and its relationship with their antioxidant property. J. Ethnopharma. 81: 155-60.

Saleem A, Husheem M, Härkönen P, Pihlaja K (2002) Inhibition of cancer cell growth by crude extract and the phenolics of Terminalia chebula retz fruit. J. Ethnopharmacol. 81: 327-36.

Vats V, Grover JK, Rathi SS (2002) Evaluation of antihyperglycemic and hypoglycemic effect of Trigonella foenum-graecum Linn, Ocimum sanctum Linn and Pterocarpus marsupium Linn in normal and alloxanized diabetic rats. J. Ethnopharmacol. 79: 95-100.

Youn JY, Park HY and Cho KH (2004) Anti-hyperglycemic activity of Commelina communis L.: inhibition of alphaglucosidase. Diabetes Res. Clin. Pract. 66S: 149-55. 